\title{
A 3D numerical simulation of a mixed convection flow in a building integrated
} photovoltaic thermal (BIPV/T) front

Malika BOUFKRI ${ }^{1}$, Btissam ABOURIDA ${ }^{1}$, Smaine KOUIDRI $^{2}$, Mohamed SANNAD ${ }^{1}$, Lahoucine BELARCHE ${ }^{1}$

${ }^{1}$ LMPEE, National School of Applied Sciences, Ibn Zohr University, BP 1136, Morocco ${ }^{2}$ LIFSE, Arts et Métiers Institute of Technology, CNAM, HESAM University, F-75013 Paris, France malika.boufkri@gmail.com

Keywords: Numerical simulation; building integrated photovoltaic thermal (BIPV/T) system; 3D mixed convection.

\begin{abstract}
In the present paper, a numerical study of mixed convection flow of a three-dimensional building integrated photovoltaic thermal front (BIPV/T) has been investigated. The configuration consists of a cubical system heated by a solar panel partition. The left wall has an inlet damper at the bottom allowing the cold air flotation in a gap between the solar panel and the opposite vertical insulated wall. The finite volume method is used to analyze the dynamic, thermal fields and the heat transfer flow of the system. The results revealed that the heat transfer rate is affected by Reynolds and Nusselt number's variations.
\end{abstract}

\section{NOMENCLATURE}

\begin{tabular}{|c|c|}
\hline $\mathrm{g}$ & Acceleration due to gravity $\left(\mathrm{m} / \mathrm{s}^{2}\right)$ \\
\hline $\mathrm{Gr}$ & Grashof number $=\beta \mathrm{gL}^{3} \Delta \mathrm{T} / \nu^{2}$ \\
\hline $\mathrm{H}$ & Height of the PV module (m) \\
\hline $\mathrm{h}$ & Inlet and outlet height (m) \\
\hline h' & $\begin{array}{l}\text { Height of the surface above the PV } \\
\text { module }(\mathrm{m})\end{array}$ \\
\hline$\ell$ & Height of the BIPV/T system (m) \\
\hline $\mathrm{L}$ & Length $(\mathrm{m})$ \\
\hline $\mathrm{Nu}$ & Nusselt Number $=\mathrm{hL} / \mathrm{k}$ \\
\hline $\mathrm{P}$ & Pressure $=N / m^{2}$ \\
\hline $\operatorname{Pr}$ & Prandtl number $=c_{p} \mu / k$ \\
\hline $\operatorname{Re}$ & Reynolds number $=u L / v$ \\
\hline
\end{tabular}

$\begin{array}{ll}\mathrm{Ri} & \text { Richardson number } \\ \mathrm{u}_{0}, \mathrm{~V}_{0}, \mathrm{w}_{0} & \text { Reference velocities }(\mathrm{m} / \mathrm{s}) \\ \mathrm{u}, \mathrm{V}, \mathrm{w} & \text { Dimensional velocities }(\mathrm{m} / \mathrm{s}) \\ \mathrm{U}, \mathrm{V}, \mathrm{W} & \begin{array}{l}\text { Non-dimensional velocity } \\ \text { components }\end{array} \\ \mathrm{x}, \mathrm{y}, \mathrm{Z} & \text { Dimensional coordinates }(\mathrm{m}) \\ \mathrm{X}, \mathrm{Y}, \mathrm{Z} & \text { Non-dimensional cartesian } \\ & \text { coordinates }\end{array}$

\section{Greek symbols}

$\alpha \quad$ Absorptivity (radiation)

$\beta \quad$ Thermal expansion coefficient $\left(\mathrm{K}^{-1}\right)$

k Thermal Conductivity (W/m.K)

$v \quad$ Kinematic viscosity $\left(\mathrm{m}^{2} / \mathrm{s}\right)$

$\rho \quad$ Density $\left(\mathrm{kg} / \mathrm{m}^{3}\right)$

$\theta \quad$ Non-dimensional fluid temperature

\section{Subscripts}

c Cold

h Hot

$\mathrm{i} ; \mathrm{j} ; \mathrm{k} \quad$ Node position

0 Reference

\section{INTRODUCTION}

Solar energy is the most promising energy resource on earth[1]. It's virtually inexhaustible, sustainable and is currently exploited by two major technological approaches: thermal and photovoltaic[2]. The new popular technology combines both methods of energy conversion. The 
photovoltaic/thermal (PV/T) device can simultaneously produce electricity and useful heat [3]. The electrical efficiency of such hybrid system reaches up to $6 \%$ and its overall efficiency (including recovered heat) is about $67.5 \%$ [4]. Thus, this technology can effectively be integrated into buildings as an architectural element providing heat and electrical power in order to reduce energy consumption[5]-[7]. However, a considerable literature has grown up around heat transfer mechanisms through numerical simulations and experimental studies.

Kaiser et al [8] studied the influence of the air gap size and the forced convection of a building integrated photovoltaic system (BIPVT) on the PV's electrical efficiency for different values of incident solar radiation and ambient temperature. The results showed that in natural convection, an aspect ratio of 0.11 decreases cell's temperature, whereas an air velocity equal to $6 \mathrm{~m} / \mathrm{s}$ increases the power output to $19 \%$ compared to natural ventilation. In the same framework, Dehra [4] investigated the energy performance of a photovoltaic solar wall and showed that the optimal values of global efficiencies obtained from experimental data were $31.4 \%$ and $37.6 \%$ for natural and forced convection respectively. Also, Agathokleous [9] analyzed the energy and the exergy efficiency of a naturally ventilated PVT collector integrated into a wall and oriented east at a vertical position $\left(90^{\circ}\right)$. He found that a gap of $0.1 \mathrm{~m}$ is sufficient to prevent the panel from overheating.

This paper presents an extension of previous works. The mixed convection taking place between the building integrated photovoltaic thermal system (BIPV/T) is analyzed numerically. Accordingly, the 3D numerical model of the working fluid flow and different heat transfer mechanisms is developed. The governing equations are discretized by the finite volume method and solved numerically using the SIMPLEC Algorithm for different Reynolds, Nusselt and Richardson numbers.

\section{ANALYSIS AND MODELLING}

\section{Problem Formulation}

The three dimensional considered configuration is presented in Fig1. It consists of a building integrated photovoltaic system (BIPV/T) in which the left vertical wall presents a flat plate PV panel, has an inlet at the bottom allowing the heat transfer fluid flotation in a gap between the solar panel and the opposite vertical insulation wall. The working fluid adopted is air $(\mathrm{Pr}=$ 0.71). The incoming air and the PV module are maintained respectively at a cold and a hot temperature while other walls are considered adiabatic.

The simulation assumptions are: i) The air flow is considered to be laminar, Newtonian and incompressible; ii) The Viscous dissipation in the energy equation is neglected; iii) the thermo-physical properties of the heat transfer fluid (HTF) are assumed constant except the density in the buoyancy force expression which uses the Boussinesq approximation.

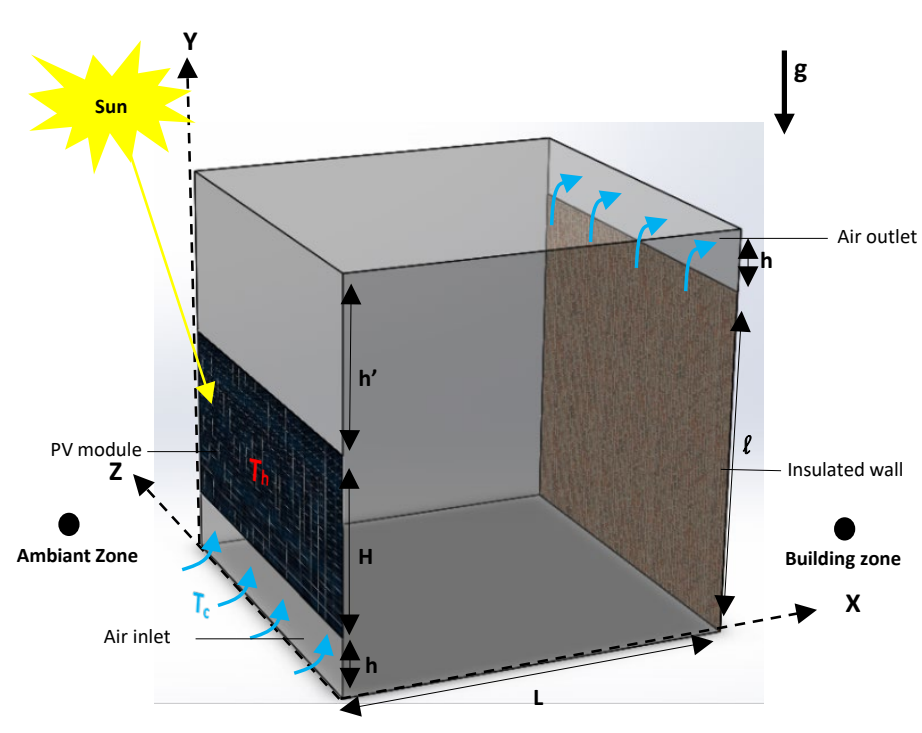

Figure 1:

The 3D configuration of the solar wall

The dimensionless equations describing both the air flow and the heat-transfer inside the $(\mathrm{BIPV} / \mathrm{T})$ system can be expressed in three dimensional forms as follows [10]:

Continuity equation:

$\frac{d U}{d X}+\frac{d V}{d Y}+\frac{d W}{d Z}=0$

Momentum equation on $\mathrm{X}$ :

$\frac{d(U U)}{d X}+\frac{d(U V)}{d Y}+\frac{d(U W)}{d Z}=-\frac{d P}{d X}+\frac{1}{R e}\left(\frac{d^{2} U}{d X^{2}}+\right.$
$\left.\frac{d^{2} U}{d Y^{2}}+\frac{d^{2} U}{d Z^{2}}\right)$ 
Momentum equation on $\mathrm{Y}$ :

$\frac{\partial(U V)}{\partial X}+\frac{\partial(V V)}{\partial Y}+\frac{\partial(V W)}{\partial Z}=-\frac{\partial P}{\partial Y}+\frac{1}{R e}\left(\frac{\partial^{2} V}{\partial X^{2}}+\right.$

$\left.\frac{\partial^{2} V}{\partial Y^{2}}+\frac{\partial^{2} V}{\partial Z^{2}}\right)+R i \theta$

Momentum equation on $\mathrm{Z}$ :

$\frac{\partial(U W)}{\partial X}+\frac{\partial(V W)}{\partial Y}+\frac{\partial(W W)}{\partial Z}=-\frac{\partial P}{\partial Z}+\frac{1}{R e}\left(\frac{\partial^{2} W}{\partial X^{2}}+\right.$

$\left.\frac{\partial^{2} W}{\partial Y^{2}}+\frac{\partial^{2} W}{\partial Z^{2}}\right)$

Equation of energy:

$\frac{\partial(U \theta)}{\partial X}+\frac{\partial(V \theta)}{\partial Y}+\frac{\partial(W \theta)}{\partial Z}=\frac{1}{R e P r}\left(\frac{\partial^{2} \theta}{\partial X^{2}}+\frac{\partial^{2} \theta}{\partial Y^{2}}+\right.$ $\left.\frac{\partial^{2} \theta}{\partial Z^{2}}\right)$

The variables used in the equations (1) to (5) are expressed in the non-dimensional form as:

$X=\frac{x}{L} ; Y=\frac{y}{L} ; \quad Z=\frac{z}{L}$

$U=\frac{u}{u 0} ; V=\frac{v}{v 0} ; W=\frac{w}{w 0}$

$P=\frac{p-p_{0}}{\rho_{0} u i^{2}} ; \theta=\frac{T-T_{c}}{T_{h}-T_{C}}$

Where $(\mathrm{U}, \mathrm{V}, \mathrm{W})$ are velocity components, $\mathrm{P}$ and $\mathrm{P}_{0}$ are respectively the pressure and the reference pressure, $\rho_{0}$ is the reference density, $T_{\mathrm{h}}$ is the hot temperature of the PV module and $\mathrm{T}_{\mathrm{c}}$ is the cold temperature of the incoming air.

\section{Numerical approach}

The main method used to evaluate and solve the Navier-Stokes and energy equations in the form of algebraic equations is the finite volume method [11]. The grid size used to run the program encoded in FORTRAN software is 61x61x61 along X, Y and $\mathrm{Z}$ directions. Also, the momentum and the continuity equations are solved numerically using the SIMPLEC (SemiImplicit Method for Pressure Linked Equations Consistent) algorithm in order to avoid the difficulty associated with the pressure determination. Then, the partial differential equations are solved by the Alternating Direction Implicit (ADI) scheme and the tridiagonal system obtained in each direction is solved using the THOMAS algorithm.

Several convergence tests have been carried out by adapting it to the configuration and the main boundary conditions. The established convergence criterion [11] of the numerical code is presented as follow:

$$
\sum_{i, j, k=1}^{i_{\max }, j_{\max }, k_{\max }} \frac{\left|\emptyset_{i, j, k}^{n+1}-\emptyset_{i, j, k}^{n}\right|}{\left|\emptyset_{i, j, k}^{n}\right|} \leq 10^{-4}
$$

$\mathrm{i}, \mathrm{j}$, and $\mathrm{k}$ indicate the grid positions, while $\mathrm{n}$ represents the iteration number. $\varnothing$ is defined as field variables $\phi(=\mathrm{U}, \mathrm{V}, \mathrm{W}, \mathrm{T}, \mathrm{P})$, in successive time steps ( $\mathrm{n}$ and $\mathrm{n}+1$ ) less than $10^{-4}$.

The main control parameters used are: Reynolds number (Re), Prandtl number (Pr), Richardson number (Ri) and Grashof number (Gr). These parameters are defined using the following expressions:

$R e=\frac{L \cdot u_{0}}{v}$

$\operatorname{Pr}=\frac{v}{\alpha}$

$R i=\frac{G r}{R e^{2}}$

$G r=\frac{g b L^{3}\left(T_{h}-T_{C}\right)}{v^{2}}$

In these expressions, $\beta, v$ and $\alpha$ are the thermal expansion coefficient, the kinematic viscosity and the thermal diffusivity, respectively.

The above-mentioned equations are associated with boundary conditions. they are given in dimensionless form as follows:

- In the air inlet: $\mathrm{U}=1 ; \mathrm{V}=\mathrm{W}=0 ; \theta=-0.5$

- On the PV module: $\mathrm{U}=\mathrm{V}=\mathrm{W}=0 ; \theta=0.5$

- On the insulation wall, horizontal walls and other vertical walls: $\mathrm{U}=\mathrm{V}=\mathrm{W}=0 ; \frac{\partial \theta}{\partial X}=$ $\frac{\partial \theta}{\partial Y}=\frac{\partial \theta}{\partial Z}=0$

- In the air outlet: $\frac{\partial U}{\partial X}=\frac{\partial V}{\partial X}=\frac{\partial W}{\partial X}=\frac{\partial \theta}{\partial X}=0$

The corresponding local Nusselt number is defined as:

$$
N u_{\text {local }}=\frac{\partial \theta}{\partial X}
$$

While, the average Nusselt presents the integral temperature flow through the solar panel and is formulated by:

$$
N u_{\text {moy }}=\frac{1}{H} \int_{h}^{h+H} \int_{0}^{1} N u_{\text {local }}(Y, Z) d Y d Z
$$




\section{RESULTS}

The purpose of the paper is to investigate the convective heat transfer flow of the cubical system as a function of temperature distribution, velocity fields and average Nusselt number. For the mixed convection, Richardson number must be set at 1 while other controlling parameters are variable. Reynolds number is changing over a range of $(30 \leq \operatorname{Re} \leq 90)$. The relative height of the heated solar $\mathrm{H} / \mathrm{L}$, the air inlet and outlet $\mathrm{h} / \mathrm{L}$, the right insulation wall $\ell / \mathrm{L}$ and the Prandtl number are fixed respectively at $0.52,0.14,0.96$ and 0.71 .

\section{Temperature distribution (Isotherms)}

For a good inspection of the temperature distribution inside the BIPV/T system, the 3D and 2D isotherms for different Reynolds numbers 30, 60 and 90 are schematized in Fig.2 and Fig3 respectively. The vertical tightening of isotherms around the left wall translates the mixed convection phenomena's establishing, in which heated PV modules interact with the incoming cold air. It's a flow heat gain explained by the induced temperature gradient. This gradient causes a variation in density that leads to the heat transfer fluid's particles movement.

This effect is highlighted for different vertical planes $(Z=0.3, Z=0.5, Z=0.7)$ in Fig.3. The flow simulation analyze indicates good components (Solar panel and other Walls) cooling. This is due to the increasing of Reynolds number that generates a rising in the inertia forces compared to the viscosity forces. Consequently, the cold air flotation is strengthened from the inlet to the outlet, which finally results in a considerable rate of heat transfer.

\section{Dynamical fields}

For more visualization of the horizontal velocity $\mathrm{U}$ component at the inlet and the outlet of the considered configuration, velocity fields are presented for $\mathrm{Y}=0.93$ and $\mathrm{Y}=0.07$ plans in the Fig.4 for different Reynolds values 30, 60 and 90. In fact, both dynamical studies show that velocity fields spread out along $X$ by increasing the value of the Reynolds number. This velocity takes considerable values at the outlet $(\mathrm{Y}=0.93)$ of the cubical system which indicate a significant fluid transport.

Also, Velocity profiles are schematized in Fig.5 for different Reynolds values 30,60 and 90. The horizontal velocity component $U$ is presented in Fig. 5 -a for $(X=0, Z=0.5),(X=0.5, Z=0.5)$ and $(\mathrm{X}=0.9, \mathrm{Z}=0.5)$ as function of $\mathrm{Y}$. The vertical velocity component $\mathrm{V}$ is presented in Fig.5-b for $(Y=0, Z=0.5),(Y=0.5, Z=0.5)$ and $(Y=0.9$, $\mathrm{Z}=0.5)$ as function of $\mathrm{X}$. These profiles emphasize that both the vertical velocity $\mathrm{V}$ and the horizontal velocity $U$ component increase with $\mathrm{X}$ and $\mathrm{Y}$ respectively, which means that the fluid is moving along both directions in the inlet, the middle and the outlet of the system. This is physically explained by the dominance of inertia force combined with thermal buoyancy from the inlet to the outlet of the building front.
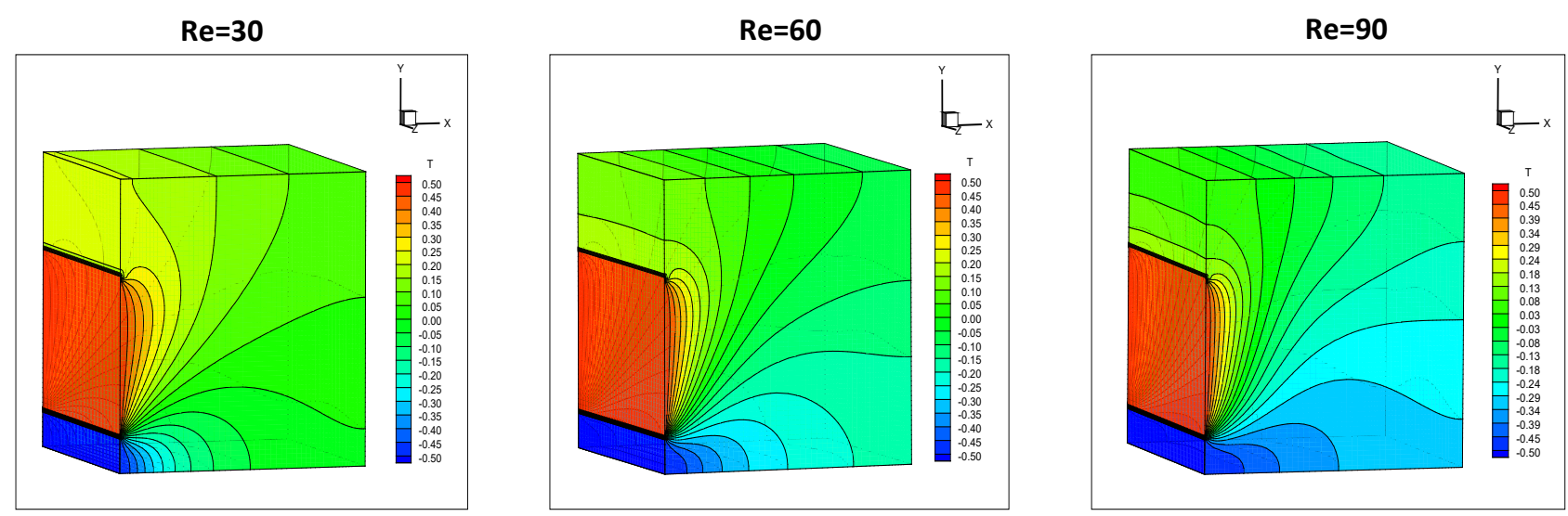

Figure 2: 3D Isotherms for $\mathrm{Ri}=1$ and different values of

$$
\mathrm{Re}=30,60,90
$$



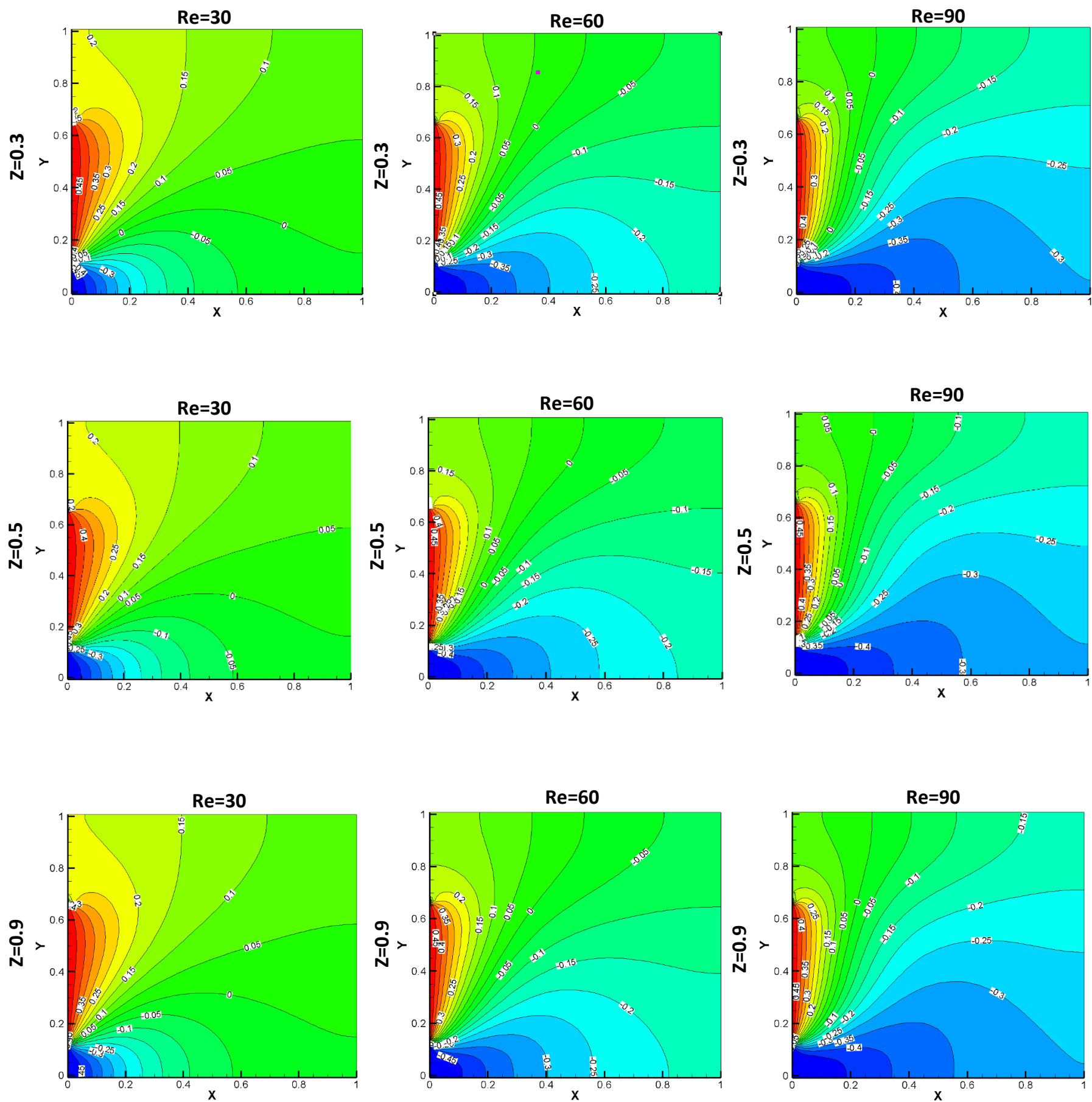

Figure 3: 2D Thermal fields for $\mathrm{Z}=0.3, \mathrm{Z}=0.5$ and $\mathrm{Z}=0.9$ plans and for different values of $\operatorname{Re}=30,60,90$. 

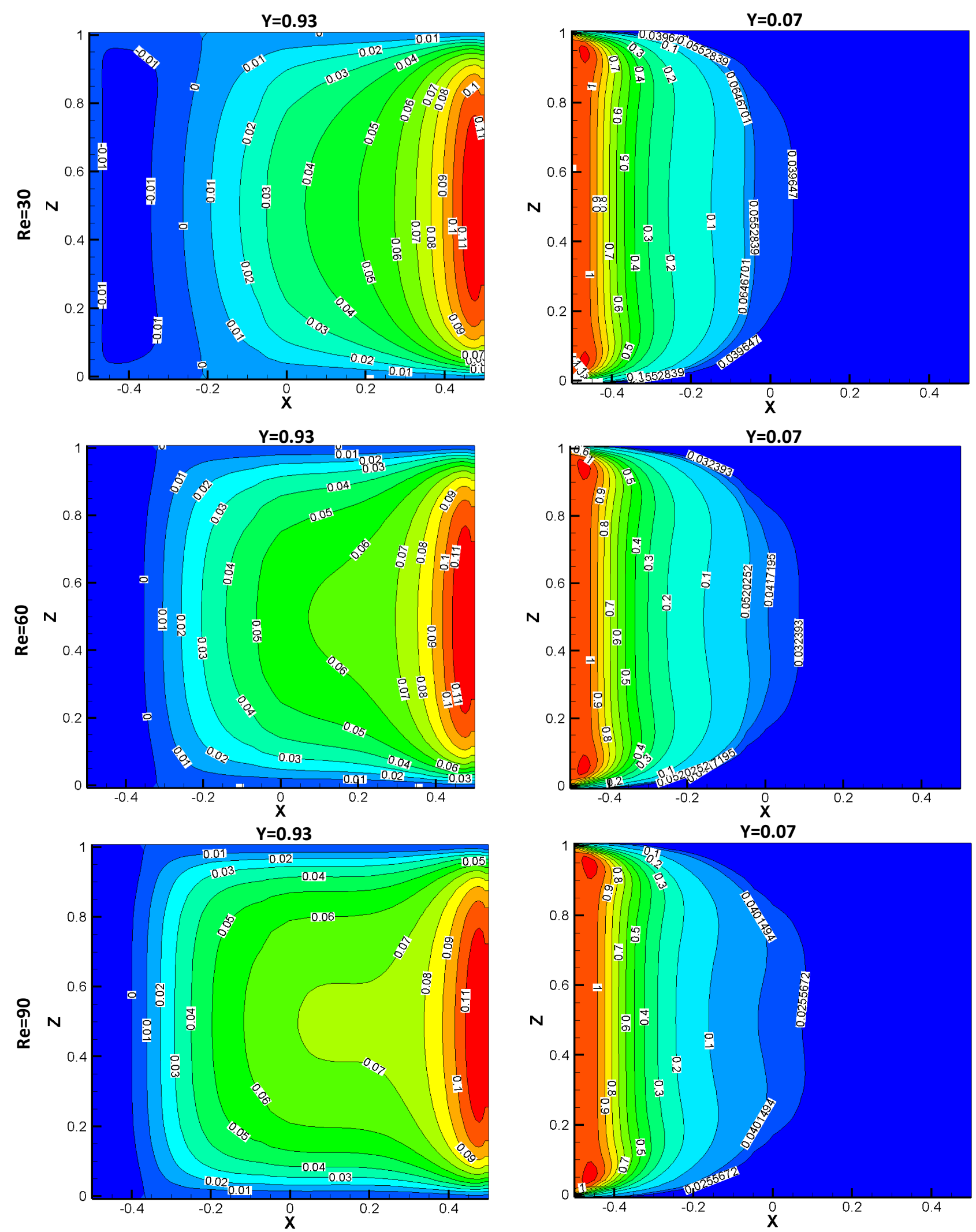

Figure 4: Dynamical fields of the horizontal velocity $\mathrm{U}$ component for $\mathrm{Y}=0.07$ and $\mathrm{Y}=0.93$ plans for different values of $\mathrm{Re}=30,60,90$. 

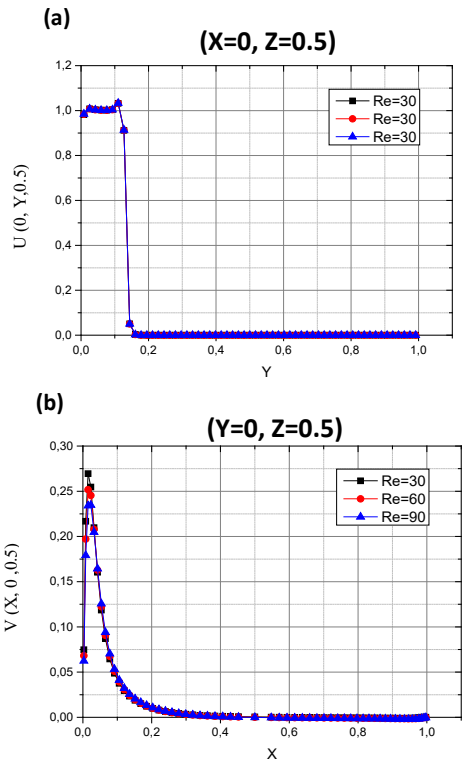
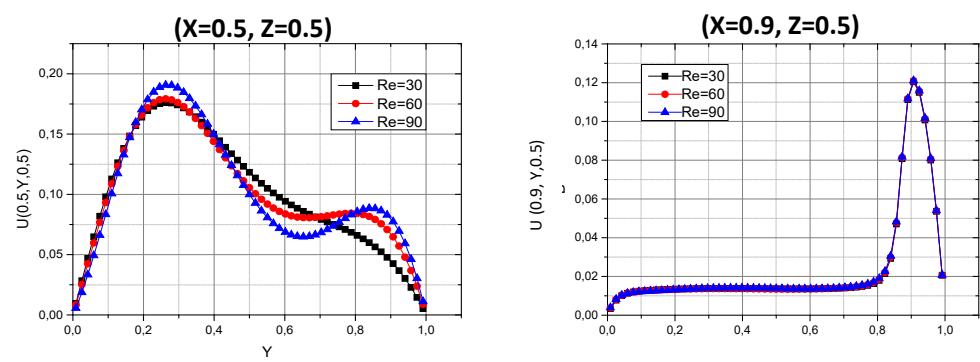

$Y$
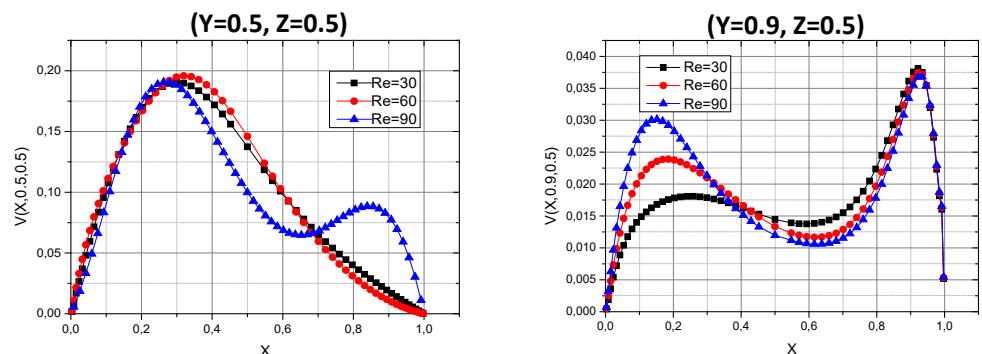

Figure 5: Vertical and horizontal velocity component's profiles for $\mathrm{Ri}=1$ and different values of $\mathrm{Re}=30,60,90$. (a)Horizontal velocity $\mathrm{U}$ component for $(X=0, Z=0.5),(X=0.5, Z=0.5)$, and $(\mathrm{X}=0.9, \mathrm{Z}=0.5)$. (b) Vertical velocity $\mathrm{V}$ component for $(\mathrm{Y}=0, \mathrm{Z}=0.5),(\mathrm{Y}=0.5, \mathrm{Z}=0.5)$, and $(\mathrm{Y}=0.9, \mathrm{Z}=0.5)$.

\section{Average Nusselt number}

Another interesting analyze to study is the convective heat transfer performance. The average Nusselt number is calculated on the solar panel in terms of Reynolds number. The results illustrated in tab. 1 show an increase in the average Nusselt with the Reynolds number. This is due to the existence of an intense temperature gradient which is reflected by a considerable heat exchange between the incoming cold air and the hot PV modules.

Table 1

Average Nusselt number for $\mathrm{Re}=30-90$

\begin{tabular}{cc}
\hline Reynolds & Average Nusselt number \\
\hline $\mathbf{3 0}$ & 14,52231 \\
$\mathbf{6 0}$ & 15,41107 \\
\hline $\mathbf{9 0}$ & 15,91828
\end{tabular}

\section{CONCLUSION}

In this paper, a detailed numerical assessment of the mixed convection of a 3D building integrated photovoltaic thermal system (BIPV/T) has been achieved. The isotherms, the dynamical fields and the average Nusselt number are analyzed in terms of different values of Reynolds number. The results show that:

- The flow behavior and temperature distribution are affected by the adopted values of Reynolds number.

- The heat transfer's rate becomes important with Reynolds number rise. This is due to the dominance of inertia and fluid buoyancy effects.

\section{REFERENCES}

1. F. Yazdanifard and M. Ameri, 'Exergetic advancement of photovoltaic/thermal systems (PV/T): A review', Renewable and Sustainable Energy Reviews, vol. 97, pp. 529-553, Dec. 2018, doi: 10.1016/j.rser.2018.08.053.

2. A. Herez, H. El Hage, T. Lemenand, M. Ramadan, and M. Khaled, 'Review on photovoltaic/thermal hybrid solar collectors: Classifications, applications and new systems', Solar Energy, vol. 207, pp. 1321-1347, Sep. 2020, doi: 10.1016/j.solener.2020.07.062. 
3. Y. Jia, G. Alva, and G. Fang, 'Development and applications of photovoltaic-thermal systems: A review', Renewable and Sustainable Energy Reviews, vol. 102, pp. 249-265, Mar. 2019, doi: 10.1016/j.rser.2018.12.030.

4. H. Dehra, 'An investigation on energy performance assessment of a photovoltaic solar wall under buoyancy-induced and fan-assisted ventilation system', Applied Energy, vol. 191, pp. 55-74, Apr. 2017, doi: 10.1016/j.apenergy.2017.01.038.

5. S. Yadav and S. K. Panda, 'Thermal performance of BIPV system by considering periodic nature of insolation and optimum tilt-angle of PV panel', Renewable Energy, vol. 150, pp. 136-146, May 2020, doi: 10.1016/j.renene.2019.12.133.

6. R. Pillai, G. Aaditya, M. Mani, and P. Ramamurthy, 'Cell (module) temperature regulated performance of a building integrated photovoltaic system in tropical conditions', Renewable Energy, vol. 72, pp. 140-148, Dec. 2014 , doi: 10.1016/j.renene.2014.06.023.

7. Y. Wang, S. Ke, F. Liu, J. Li, and G. Pei, 'Performance of a building- integrated photovoltaic/thermal system under frame shadows', Energy and Buildings, vol. 134, pp. 71-79, Jan. 2017, doi: 10.1016/j.enbuild.2016.10.012.

8. A. S. Kaiser, B. Zamora, R. Mazón, J. R. García, and F. Vera, 'Experimental study of cooling BIPV modules by forced convection in the air channel', Applied Energy, vol. 135, pp. 88-97, Dec. 2014, doi: 10.1016/j.apenergy.2014.08.079.

9. R. A. Agathokleous, S. A. Kalogirou, and S. Karellas, 'Exergy analysis of a naturally ventilated Building Integrated Photovoltaic/Thermal

(BIPV/T) system', Renewable Energy, vol. 128, pp. 541-552, Dec. 2018, doi: 10.1016/j.renene.2017.06.085.

10. H. Doghmi, B. Abourida, L. Belarche, M. Sannad, and M. Ouzaouit, 'Effect Of The Inlet Opening On Mixed Convection Inside A 3-D Ventilated Cavity', Thermal Science, vol. 22, no. 6, p. 12, 2018.

11. S. V. PATANKAR, 'Numerical Heat Transfer and Fluid Flow'. CRC press, 1980. 